\title{
Organic carbon content of sediments as an indicator of stress in the marine benthos
}

\author{
J. Hyland ${ }^{1, *}$, L. Balthis ${ }^{1}$, I. Karakassis ${ }^{2}$, P. Magni ${ }^{3}$, A. Petrov ${ }^{4}$, J. Shine ${ }^{5}$, \\ O. Vestergaard ${ }^{6}$, R. Warwick ${ }^{7}$ \\ ${ }^{1}$ National Oceanic and Atmospheric Administration, National Ocean Service, 219 Ft. Johnson Road, Charleston, \\ South Carolina 29412, USA \\ ${ }^{2}$ Marine Ecology Lab, Biology Department, University of Crete, Heraklion, 71409 Crete, Greece \\ ${ }^{3}$ IMC International Marine Centre, Località Sa Mardini, 09072 Torregrande-Oristano, Italy \\ ${ }^{4}$ National Academy of Sciences of Ukraine, Institute of Biology of the Southern Seas, 2 Nakhimov Ave., Sevastopol 99011, Ukraine \\ ${ }^{5}$ Harvard School of Public Health, Harvard University, 401 Park Drive, PO Box 1567, Boston, Massachusetts 02125, USA \\ ${ }^{6}$ Intergovernmental Oceanographic Commission (IOC), United Nations Educational Scientific and Cultural Organization, \\ 1 rue Miollis, 75732 Paris Cedex 15, France \\ ${ }^{7}$ Plymouth Marine Laboratory, Prospect Place, West Hoe, Plymouth PL1 3DH, UK
}

\begin{abstract}
While organic matter in sediments is an important source of food for benthic fauna, an overabundance can cause reductions in species richness, abundance, and biomass due to oxygen depletion and buildup of toxic by-products (ammonia and sulphide) associated with the breakdown of these materials. Moreover, increasing organic content of sediment is often accompanied by other chemical stressors co-varying with sediment particle size. In the present study, synoptic data on the structure of macroinfaunal communities and total organic carbon (TOC) content of sediment were obtained from 951 stations representing 7 coastal regions of the world: the northern Black Sea (Crimean and Caucasian coasts); eastern Mediterranean Sea (Greece); North Sea (Ekofisk oil field); Firth of Clyde and Liverpool Bay, UK; Seto Inland Sea, Japan; Boston Harbor and Massachusetts Bay, USA and estuaries of the southeastern USA. Macroinfaunal and TOC data were examined to look for patterns of association consistent with conceptual model predictions and to identify TOC critical points corresponding to major shifts in the benthic data. Species richness, Hurlbert's $E\left(S_{n}\right)$, was selected as the primary response parameter. Results suggested that risks of reduced species richness from organic loading and other associated stressors in sediments should be relatively low at TOC concentrations less than about $10 \mathrm{mg} \mathrm{g}^{-1}$, high at concentrations greater than about $35 \mathrm{mg} \mathrm{g}^{-1}$, and intermediate at concentrations in between. Predictive ability across these ranges was high based on results of re-sampling simulation. While not a measure of causality, it is anticipated that these TOC critical points may be used as a general screening-level indicator for evaluating the likelihood of reduced sediment quality and associated bioeffects over broad coastal areas receiving organic wastes and other pollutants from human activities.
\end{abstract}

KEY WORDS: Marine benthos $\cdot$ Total organic carbon $\cdot$ TOC $\cdot$ Benthic-TOC relationships $\cdot$ Ecological indicators $\cdot$ Pollution impacts $\cdot$ Benthic species richness

\section{INTRODUCTION}

A common approach to assessing risks to ecosystem health is the characterization of stressors and corresponding effects through the use of indicators (Fisher et al. 2001). An ecological indicator is an attribute of the ecosystem, either biological, chemical, or physical, that is sufficiently correlated with an endpoint of concern to serve as a surrogate measure of that endpoint (Cairns et al. 1993). For an indicator to serve as a valid measure of condition, there must be a conceptual link between the presence/absence of the indicator and the state of the ecological function at risk. Secondly, a good indicator should be amenable to measurement 
and preferably easy to measure. Most importantly, the expression of the indicator should convey information that is meaningful to decision-making with respect to the risk of concern (Fisher et al. 2001). Accordingly, an important function of indicators is the identification of stressor-response relationships and corresponding thresholds for management action. As noted by Fisher et al. (2001), because of the complexity of most stressor-response relationships in nature, it is usually impractical if not impossible to completely characterize all contributing variables; thus, a common approach in the use of an indicator is to focus on a select set of factors that are pivotal to understanding the targeted risk and that involve some degree of uncertainty.

The benthos is an effective place to look for indicators of human-induced stress in coastal marine ecosystems. Benthic fauna are important components of these systems, playing vital roles in detrital decomposition, nutrient cycling, and energy flow to higher trophic levels. Moreover, benthic fauna live in close association with bottom substrata, where organic pollutants and chemical contaminants tend to accumulate and where low-oxygen conditions are typically the most severe. Because of their relatively sedentary existence, it is difficult for these organisms to avoid exposure to pollutants and other adverse conditions in their immediate surroundings. Measures of the ambient benthic community reflect the sensitivities of multiple species and life stages to pollutants that may have been building up in the sediment and affecting the fauna over many generations (Hyland et al. 1999).

Organic matter in surface sediments is an important source of food for benthic fauna (Sanders 1958, Gray 1974, Pearson \& Rosenberg 1978, Lopez \& Levinton 1987, papers in Lopez et al. 1989, Snelgrove \& Butman 1994). However, an overabundance may lead to reductions in species richness, abundance, and biomass due to oxygen depletion and buildup of toxic by-products (ammonia and sulphide) associated with the breakdown of these materials (Pearson \& Rosenberg 1978, Diaz \& Rosenberg 1995, Gray et al. 2002). Increases in the organic content of sediment also may be accompanied by increases in chemical contaminants that are co-varying in relation to a common environmental factor (e.g. increasing proportions of finer-grained sediment particles that would provide greater surface area for sorption of both organic and other chemical pollutants) (Landrum \& Robbins 1990, Lamberson et al. 1992, Thompson \& Lowe 2004). Thus, benthic fauna, especially those in muddy depositional environments, must often cope with multiple, co-occurring stressors.

Pearson \& Rosenberg (1978) developed a graphic model (Fig. 1A) to describe a generalized pattern of response of benthic communities in relation to organic enrichment. A modification of this conceptual model is presented here in Fig. 1B to demonstrate the relationships between organic enrichment, benthic response, and other related environmental factors, including oxygen depletion and presence of other co-varying, sediment-associated stressors (e.g. ammonia, sulphides, chemical contaminants). Similarly, in a recent review of models of benthic responses to eutrophication, Gray et al. (2002) expounded on the importance of such factors, further suggesting that major effects on the benthos in relation to organic enrichment result from hypoxia rather than eutrophication per se. Thompson \& Lowe (2004), who observed a close association between presence of impaired benthic assemblages and high levels of both chemical contaminants and organic matter in sediments of the San Francisco estuary, California, also used a modification of the Pearson-Rosenberg ( $\mathrm{P}-\mathrm{R})$ model to characterize benthic responses to such combined stressor gradients.

In accordance with this conceptual model, benthic faunal variables would be expected to increase in rela-

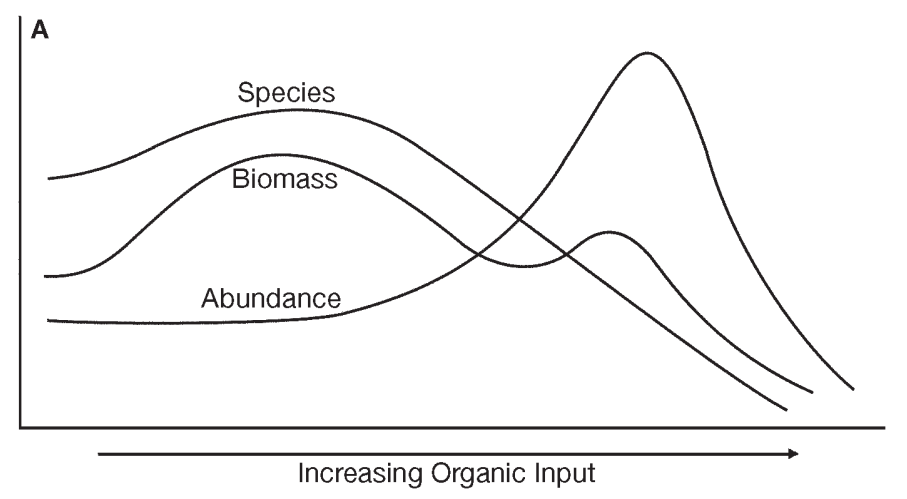

B

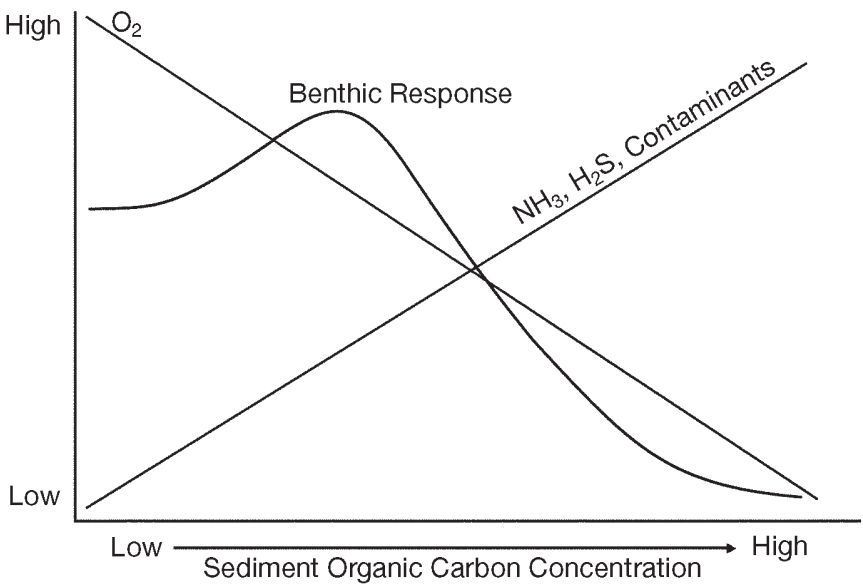

Fig. 1. Conceptual models of benthic response to organic enrichment. (A) The Pearson \& Rosenberg (1978) (P-R) model of species, abundance, and biomass patterns in relation to increasing organic input (note that the original $\mathrm{P}-\mathrm{R}$ figure showed organic matter decreasing from left to right along the $x$-axis). (B) A modification of the P-R model showing a generalized pattern of benthic response in relation to total organic carbon and other potential co-varying sediment-associated stressors 
tion to increasing organic matter (expressed here as total organic carbon, TOC) up to a certain point, and then begin to decline (Fig. 1B). For simplicity, we have used a single curve to characterize this generalized response, though it is recognized that benthic species richness, abundance, and biomass may follow somewhat different paths (as presented in the original $\mathrm{P}-\mathrm{R}$ model). The biotic-response curve in Fig. 1B most closely resembles the curve for species richness in the original P-R model (Fig. 1A). Species richness typically will be at its peak at low to slightly moderate TOC levels, due to a combination of the nutritional value of organic matter available as food, a low incidence of environmental stressors, and the co-existence of species with varying tolerance levels and recruitment strategies. As TOC increases toward the higher end of the scale, the benthos is exposed to increasing amounts of physiological stress from oxygen depletion (due to higher biological oxygen demand, BOD) and related by-products of the organic decomposition process (ammonia and sulphides). Concurrently, higher levels of TOC often correlate with increasing concentrations of other potential co-varying stressors (e.g. chemical contaminants). Species richness typically will show a gradual decline over the intermediate TOC range, as increasing numbers of sensitive species fail to survive. In contrast, in accordance with the $\mathrm{P}-\mathrm{R}$ model, other benthic variables may continue to increase throughout the intermediate range (abundance), or exhibit secondary peaks (biomass), due to the presence of heartier opportunistic species that are able to flourish under the increasingly harsh conditions and reduced competition, as the more sensitive species decline. At very high TOC concentrations, associated environmental stressors will exceed the physiological tolerance limits of a large percentage of species, leading to a sharp decline in most benthic variables. Typically, benthic assemblages under such conditions will be dominated by a few pollution-tolerant, r-selected opportunistic species. Disturbances that are too severe may eliminate even the heartiest species, resulting in azoic conditions. The $\mathrm{P}-\mathrm{R}$ model (Pearson \& Rosenberg 1978) of highest species richness at slightly moderate levels of organic enrichment is also supported by the broader 'intermediate disturbance hypothesis' (Grime 1973, Horn 1975, Connell 1978, review by Wilkinson 1999), which invokes alternative theoretical mechanisms to explain the same phenomenon.
Given these patterns, it should be possible to identify TOC critical points indicative of low to high risks of related adverse environmental conditions leading to stress in the benthos. Desirable attributes of such an indicator are linkage to a conceptual framework, high predictive ability, ease of use, and broad management applicability. In this paper, we present results of our efforts to develop such an indicator, using test data sets from 7 different locations around the world (Fig. 2). Synoptic measurements of macroinfauna, concentrations of TOC, and other environmental variables were examined across the various data sets to look for consistent patterns of association and to identify TOC critical points corresponding to major shifts in the benthic data. We must caution that it is not our intention for these critical points to serve as measures of causality (i.e. to imply that the observed bioeffect was caused by TOC itself). Rather, our premise is that because TOC tends to correlate with factors causing ecological stress (e.g. low dissolved oxygen, high ammonia and sulphide, chemical contamination of sediments), then TOC, in turn, may serve as a simple screening-level indicator, or symptom, of such stress.

\section{MATERIALS AND METHODS}

Data were obtained from 951 stations from 7 coastal regions on 3 different continents (Fig. 2, Table 1). General features of these data sets are as follows:

Northern Black Sea: 72 stations from multiple sampling efforts conducted along the Crimean and Caucasian coasts, in locations ranging from non-polluted

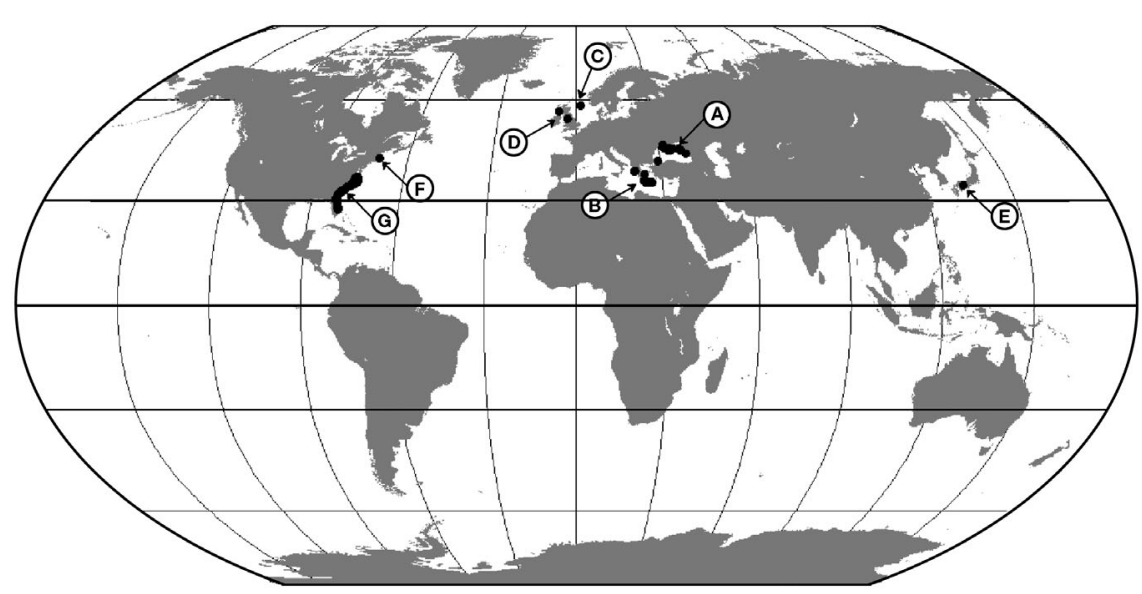

Fig. 2. Study areas: (A) northern Black Sea (along Crimean and Caucasian coasts); (B) eastern Mediterranean Sea (along the coast of Crete); (C) North Sea (near Ekofisk oil rig); (D) Firth of Clyde and Liverpool Bay, UK $\mathrm{U}_{i}$ (E) an estuary of the Seto Inland Sea, Japan; (F) Boston Harbor and Massachusetts Bay, USA; and (G) estuaries of the SE USA (Cape Henry, Virginia, to St. Lucie Inlet, Florida) 
Table 1. Sources of data used to investigate the relationship between organic carbon and benthic species richness. Letters next to study areas refer to location codes in Fig. 2. TOC: total organic carbon (measured on a CHN analyzer); OM: organic matter content (measured by mass loss on ignition). In cases where carbon was measured as OM, values were multiplied by a factor of 0.33 to estimate TOC (Leong \& Tanner 1999). All samples were taken from the upper surface layer of sediment $(<5 \mathrm{~cm})$

\begin{tabular}{|c|c|c|c|c|c|}
\hline Study Area & No. samples & Sampling period (years) & $\begin{array}{l}\text { Sampler } \\
\left(\mathrm{m}^{2}\right)\end{array}$ & $\begin{array}{l}\text { Sieve } \\
(\mathrm{mm})\end{array}$ & $\begin{array}{l}\text { Carbon } \\
\text { method }\end{array}$ \\
\hline Northern Black Sea (A) & 721976 & 6-1977, 1979-1986, 1988-1989, 1992 & 0.25 & 1.0 & TOC \\
\hline Eastern Mediterranean Sea (B) & 199 & 1986-1987, 1993, 1995-1997 & 0.10 & 0.5 & TOC \\
\hline North Sea $(C)$ & 39 & 1987 & 0.10 & 1.0 & OM \\
\hline Firth of Clyde and Liverpool Bay, UK (D) & 31 & $1981,1983,1991$ & 0.10 & 1.0 & TOC \\
\hline Estuary of Seto Inland Sea, Japan (E) & 18 & $1994-1995$ & 0.04 & 1.0 & TOC \\
\hline Boston Harbor and Massachusetts Bay, USA (F) & 303 & $1991-1999$ & 0.04 & 0.3 & TOC \\
\hline Estuaries of southeastern USA $(\mathrm{G})$ & 289 & $1994-1997$ & 0.04 & 0.5 & TOC \\
\hline
\end{tabular}

sites within boundaries of marine reserves and other protected areas to sites severely polluted from organic enrichment and petroleum contamination. Samples are from sites with water depths of 5 to $92 \mathrm{~m}$ and a salinity range of 16 to 24 practical salinity units (PSU) (most sites < 18 PSU) (Mironov 1992, Petrov 2000a,b). Present study contact was A. Petrov.

Eastern Mediterranean Sea: 199 stations from multiple sampling efforts conducted along the upper continental shelf of Crete (Karakassis \& Eleftheriou 1997), in Heraklion Harbor (Lampadariou et al. 2000), and in the Aegean and eastern Ionian Seas (Karakassis et al. 1999, 2000). Samples are from sites with water depths of 10 to $190 \mathrm{~m}$ and salinity >38 PSU. Present study contact was I. Karakassis.

North Sea: 39 offshore stations radiating from an active drilling platform at the Ekofisk oilfield (Gray et al. 1990). Stations are in fully marine areas (salinity $>34$ PSU), with depths of about $76 \mathrm{~m}$. Present study contact was R. Warwick.

Liverpool Bay, Firth of Clyde: Liverpool Bay samples are from 7 offshore stations (4 replicates each) along a transect extending across a dredging disposal site following the $10 \mathrm{~m}$ depth contour (Somerfield et al. 1995). Firth of Clyde samples are from 24 offshore stations, consisting of 12 from each of 2 transects extending across the Garroch Head sewage-sludge dumping ground, at depths of 64 to 194 m (Pearson \& Blackstock 1984). All stations are in fully marine areas (salinity >34 PSU). Present study contact was R. Warwick.

Seto Inland Sea (Japan): samples are from 3 stations sampled 6 times within an estuarine subtidal zone. Low-tide water depths ranged from 4 to $8 \mathrm{~m}$, with a near-bottom salinity range of 31 to 34 PSU (Magni 1998). Present study contact was P. Magni.

Boston Harbor, Massachusetts Bay: 303 stations from Boston Harbor, a highly contaminated, shallow, urban estuary in Massachusetts, USA, and from more pristine coastal locations nearby in Massachusetts Bay. Stations are from depths of 3 to $50 \mathrm{~m}$, with a salinity range of
20 to 33 PSU. (Blake et al. 1998). Present study contact was J. Shine.

SE US estuaries: 289 subtidal stations sampled during the summers 1994 to 1997 in estuaries from Cape Henry, Virginia, to St. Lucie Inlet, Florida. Samples are from depths of 0.5 to $16 \mathrm{~m}$, with a salinity range of 0 to 39 PSU. These estuaries receive a wide range of organic and chemical stressors originating from multiple sources. However, co-occurrences of impaired benthic condition and adverse exposure condition (sediment contamination and/or toxicity) are limited to a relatively small percentage of the region's total estuarine area (estimated at less than about $25 \%$, Hyland et al. 1998). Present study contact was J. Hyland.

All stations were represented by similar matching sets of macroinfaunal and TOC data. There were some differences in methods used to generate the data among the various studies (e.g. variations in sieve sizes, surface area of sampling gear, method of organic matter determination; Table 1); however, steps were included in the present analysis to account for such differences. For example, as described in more detail below, the primary measure of biological response was based on a variable that is relatively independent of sample-size differences caused by variations in sieve sizes and gear type. Also, in the few cases (39 of 951 samples) where organic carbon was measured as organic-matter content by mass loss on ignition (MLOI), rather than TOC by a CHN analyzer, these values were reduced by a factor of 3 to convert to TOC and correct for the overestimation of organic carbon associated with the MLOI methodology (Leong \& Tanner 1999).

A major objective of the study was to compare data across the various locations to describe the overall pattern of benthic response in relation to increasing TOC and to identify TOC critical points indicative of low versus high risks of impaired benthic condition. There is no doubt that benthic species can vary in relation to a complexity of other interacting environmental 
factors (see 'Discussion'). However, in order to make maximum use of the various data sets, no attempt was made to exclude samples to partition out the influences of such factors, as much of this knowledge was unattainable for one thing. For example, while it is understood that factors related to the quality, bioavailability, fluxes, and utilization (ingestion and assimilation) of organic matter as a food source are particularly strong determinants of benthic species distributions (Gray 1974, Tenore et al. 1982, Lopez \& Levinton 1987 , papers in Lopez et al. 1989, Snelgrove \& Butman 1994), the present analysis was conducted with data from prior field studies that did not include such measurements, and thus it was impossible to go back and account for their effects. Moreover, for some other determinants, partitioning the data sets to account for their effects would interfere with the underlying goal of examining benthic responses across broad geographic regions and TOC concentration ranges. For example, excluding stations with chemically contaminated sediments would also exclude many stations with high TOC (given that both are highly inversely correlated with grain size). The intention here was to examine patterns of benthic response in relation to increasing TOC, without controlling for such differences, thereby testing the robustness of TOC as a screening-level indicator (or symptom) of stress over as broad of a range in conditions as possible.

Numbers of individuals of each benthic species (or lowest practical taxon) in a sample were recorded by station and study region. Though a variety of benthic variables were calculated from these count data, species richness, based on Hurlbert's $E\left(S_{n}\right)$ (Hurlbert 1971), was selected for further analysis of benthic- TOC relationships. $E\left(S_{n}\right)$ is the expected number of species present in an increasingly rarefied sample of $n$ individuals randomly selected (without replacement) from a finite collection of $N$ individuals and $S$ species. With this measure, meaningful comparisons of species richness among collections of different sizes can be made by adjusting the collections to a common size $(n)$. Thus, this measure was especially suitable for the present study in which we sought to examine species richness in relation to TOC among samples collected with varying types of sampling gear. Note, however, that $E\left(S_{n}\right)$ is not

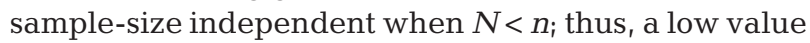
of $n(n=10)$ was chosen so that low-density samples (especially from the Black Sea) could be included in the analysis. In addition to its conceptual basis for samplesize independence (Hurlbert 1971), $E\left(S_{n}\right)$ at $n=10$ was shown to be highly independent of sample-size differences in computer simulations run on a variety of diversity indices with data from this study.

Simple $x-y$ plots of benthic species richness versus TOC concentration were generated as a tool for exam- ining basic patterns in the data and comparing them against the conceptual model. TOC concentration $\left(\mathrm{mg} \mathrm{g}^{-1}\right.$, plotted on the $x$-axis) was divided initially into 10 discrete intervals as follows: $\leq 2.5,>2.5-5,>5-10$, $>10-15,>15-20,>20-25,>25-30,>30-35$, > 35-40, and $>40$. Mean species richness among stations within a specific TOC interval, and the $95 \%$ confidence intervals, were plotted across each of the TOC intervals. The resulting curve was examined to look for obvious breakpoints in the data. The inflection points of greatest concern with respect to evaluating potential adverse effects in relation to increasing TOC are the lower TOC critical point at which species richness starts to decline and the upper TOC critical point at which the decline starts to level out. Thus, for the identification of TOC critical points, we have used graphic models that ignore the initial increase in species richness at low TOC levels below the lower inflection point in the conceptual model.

Two quantitative methods were used to determine the location of these 2 critical points where changes in TOC were associated with the largest changes in species richness. In the first approach, we used ANOVA as an exploratory tool to identify TOC critical points that maximized differences in species richness among the 3 TOC ranges resulting from various combinations of upper and lower TOC values. Upper and lower TOC critical points were derived by selecting the 2 values that produced the highest F-statistic (Sokal \& Rohlf 1981). In the second approach, a standard sigmoid dose-response curve was fitted to the data using nonlinear, least-squares regression (Bates \& Watts 1988). The function was of the form:

$$
f(x)=a_{0}+a_{1} /\left(1+\mathrm{e}^{a_{2}+a_{3} x}\right)
$$

where $x$ is TOC $\left(\mathrm{mg} \mathrm{g}^{-1}\right)$ and $a_{0}, a_{1}, a_{2}$, and $a_{3}$ are parameters selected by the regression procedure to minimize the sum of squared deviations from the fitted curve. Upper and lower TOC critical points were derived from the inflection points of the fitted curve. The inflection points were calculated by determining minima and maxima of the second derivatives.

The regression method was applied again using a modification of the above equation that included categorical site variables to test for variation in species richness related to geographical location. The form of this function was:

$$
f(x)=a_{0}+a_{1} /\left(1+\mathrm{e}^{a_{2}+a_{3} x}\right)+a_{4} L_{1}+a_{5} L_{2} \ldots+a_{9} L_{6}
$$

where $x$ and a parameters are defined as before, and the terms $L_{1}$ to $L_{6}$ are categorical values (either 0 or 1 ) used to describe location of the data (i.e. northern Black Sea, eastern Mediterranean Sea, etc.). Curves were fitted to the combined data sets multiple times, each time allowing a different individual data set to 
serve as a reference location and the remaining ones to exert their influence relative to the reference location. This latter modification of the regression function provided a test as to whether any single geographic location unduly influenced the derivation of TOC critical points.

The 2 TOC critical points determined from each analysis were used to separate samples into 3 groups of low, medium, and high levels of TOC. To evaluate the predictive ability of these critical points as indicators of change in benthic species richness, a re-sampling simulation (Lunneborg 1999) was used to estimate the probability of observing reduced species richness with increasing TOC across these 3 ranges. Simulations consisted of 10 iterations of 250 pairwise comparisons of randomly selected samples (with replacement) from each group. Probabilities of reduced species richness were computed for the following combinations: $E\left(S_{10}\right)$ in low TOC range $>E\left(S_{10}\right)$ in medium TOC range; $E\left(S_{10}\right)$ in low TOC range $>E\left(S_{10}\right)$ in high TOC range; $E\left(S_{10}\right)$ in medium TOC range $>E\left(S_{10}\right)$ in high TOC range. These probabilities, which can range from 0.5 to 1.0 , are a measure of the power of a critical point in separating samples with higher and lower species richness. Probabilities closer to 1.0 are indicative of critical points with higher discriminatory power, while probabilities close to 0.5 indicate that TOC alone has no explanatory power with respect to reductions in species richness. Type I error probabilities were computed as a basis for testing the null hypothesis that when comparing samples taken from 2 groups, the probability of observing reduced species richness in the higher TOC range is equal to 0.5 based on 1-sided $t$-tests.

All statistical tests were conducted using either SAS (SAS Institute) or S-Plus (Math Soft).

\section{RESULTS}

\section{TOC-species richness patterns and critical points}

The overall pattern of species richness in relation to TOC was consistent with conceptual-model predictions, with a maximum in the low TOC range, a gradual decline over the intermediate TOC range, and a minimum in the high TOC range (Fig. 3A). This was a suitable pattern for identifying ranges in TOC that could be used to assess low, moderate, and high risks of an impaired benthos. Total faunal abundance, which we also looked at initially, was much less appropriate for such a purpose, because of the absence of a lower-end inflection point at which the curve begins to show a gradual decline. Instead, abundance increased over a much broader TOC range, as would be predicted by
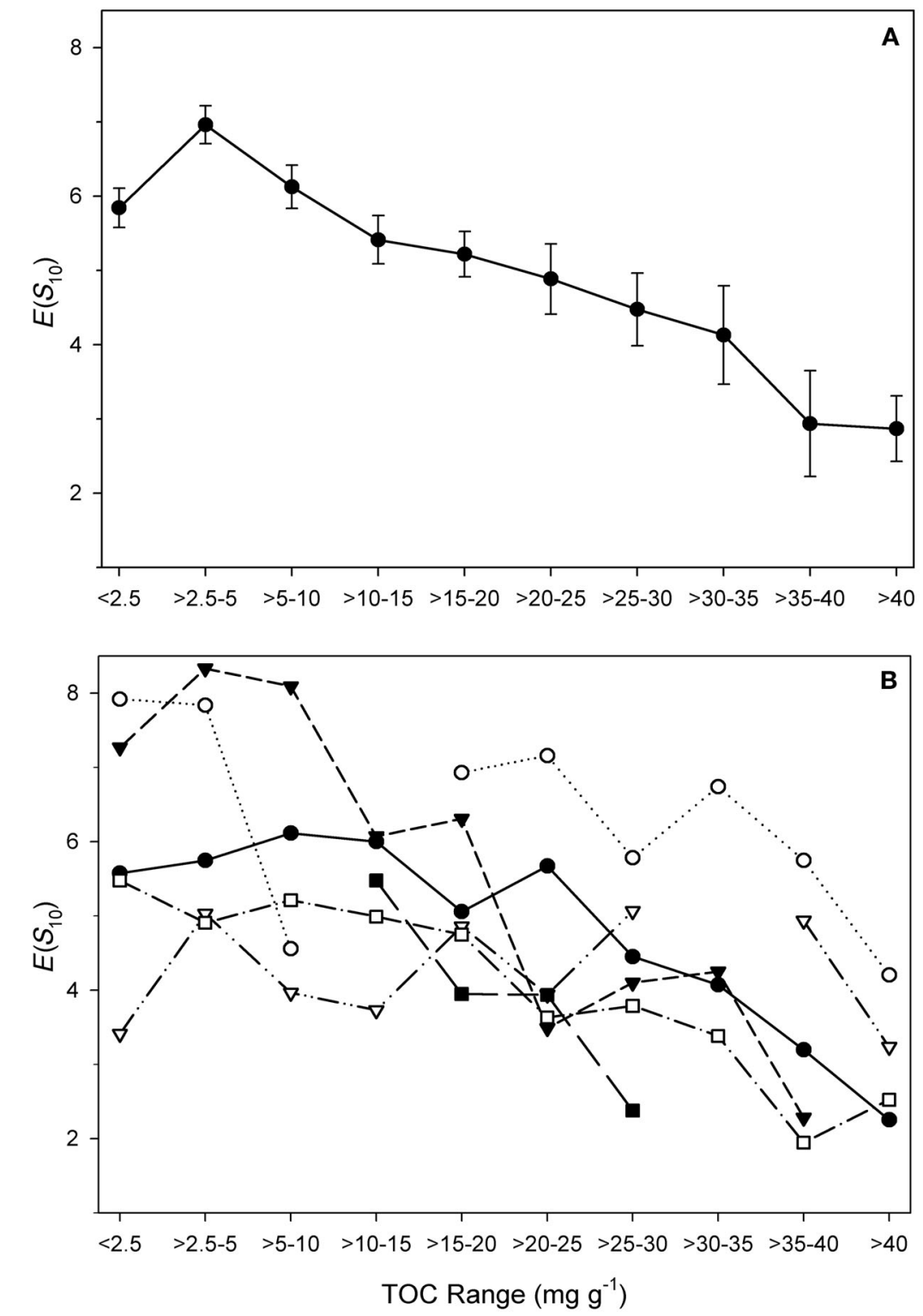

Fig. 3. Plot of mean species richness, $E\left(S_{10}\right)$ within different ranges of total organic carbon (TOC, $\mathrm{mg} \mathrm{g}^{-1}$ ). (A) All data sets combined (vertical lines are $95 \%$ confidence intervals); (B) individual regions (regions are indicated by symbols - B: Boston Harbor and Massachusetts Bay, USA; O: North Sea/ coastal UK; $\boldsymbol{\nabla}$ : eastern Mediterranean Sea; $\nabla$ : northern Black Sea; $\mathbf{\square}$ : Seto Inland Sea, Japan; $\square$ : estuaries of the SE USA) 
the conceptual model, until it finally declined at the uppermost end of the TOC scale (plot not included here). While the abundance pattern was consistent with the conceptual model prediction, the species data serve as a more sensitive measure of pollution responses addressed here. Thus, there was no further consideration of abundance, and, as noted earlier, the remaining focus was on the development of TOC critical points for evaluating risks of reductions in benthic species richness.

Mean values of $E\left(S_{10}\right)$ peak at TOC concentrations between about 2.5 and $5 \mathrm{mg} \mathrm{g}^{-1}$, begin declining between 5 and $10 \mathrm{mg} \mathrm{g}^{-1}$, and then reach a minimum of around 35 to $40 \mathrm{mg} \mathrm{g}^{-1}$ (Fig. 3A). Thus, the desired lower and upper TOC critical points appear to be within these 2 latter intervals. As described above, 2 different quantitative methods were used to help pinpoint their location: Method 1, selecting the 2 values that produced the highest $F$-statistic from a series of ANOVAs performed on various combinations of upper and lower TOC values, and Method 2, calculating inflection points of a sigmoid dose-response function fitted to the original benthic-TOC data. Under Method 1, a maximum F-statistic of 172 was found at lower and upper TOC critical points of 8 and $36 \mathrm{mg} \mathrm{g}^{-1}$, respectively. Mean differences among the resulting 3 TOC ranges defined by these 2 values were highly significant $(p<0.0001, d f=2)$, even after applying a Bonferroni correction to account for multiple comparisons. Method 2 produced very similar results (Fig. 4). Lower and upper inflection points along the fitted doseresponse curve (based on Eq. 1) were found at corresponding TOC values of 10 and $35 \mathrm{mg} \mathrm{g}^{-1}$. Although the variance explained by the model was modest $\left(\mathrm{r}^{2}=\right.$ $0.25)$ due to wide scatter in the raw data, the $F$-statistic from the regression analysis was highly significant $(F=$ $107, p<0.001)$, suggesting a significant overall pattern of decreasing species richness with increasing TOC (regardless of the exact mode of causality).

The modest $r^{2}$ value from the above regression model is due in part to regional differences. For example, while there is an overall pattern of decreasing species richness with increasing TOC, Fig. 3B reveals that there is variability in the paths (mostly the heights) of individual regional curves. In fact, when Eq. 2 was used in the regression analysis, thereby accounting for variations in species richness related to geographic location, the amount of variance explained by the regression model improved substantially $\left(r^{2}=0.62\right)$. However, an important point is that the position of inflection points derived from Eq. (2) remained the same regardless of which data sets were used as reference locations. Values of the fitted curves at the $y$ intercept (based primarily on the $a_{0}$ and $a_{1}$ terms) varied somewhat with each new reference-location designation; however, the positions of the TOC inflection points (based primarily on the $a_{2}$ and $a_{3}$ terms) did not change regardless of location (graphics not included here). Thus, results of the regression analysis also provided evidence that the derivation of TOC critical points from the combined data was not unduly influenced by any individual geographic location.

Given that both derivation methods ( $F$-statistic and regression) produced very similar results, for rounding simplicity, TOC concentrations of 10 and $35 \mathrm{mg} \mathrm{g}^{-1}$ were selected as lower and upper critical points for further analysis. Thus, the likelihood of observing a decline in benthic species richness in relation to increasing TOC is expected to be relatively low at concentrations less than about $10 \mathrm{mg} \mathrm{g}^{-1}$, high at concentrations greater than about $35 \mathrm{mg} \mathrm{g}^{-1}$, and intermediate at concentrations in between. As a side note, substitution of $H^{\prime}$ (Shannon \& Weaver 1949) for $E\left(S_{10}\right)$ as a response variable gave a similar pattern as in Fig. 3A, with identical TOC critical points at 10 and $35 \mathrm{mg} \mathrm{g}^{-1}$, thus providing further validation of the 
above results. However, as explained, we have chosen to use $E\left(S_{10}\right)$ as the primary response variable because of its known sample-size independence.

\section{Predictive ability of TOC critical points}

Results of re-sampling simulation (Table 2) indicated that there is a very high probability of having high, medium, and low mean species richness within low, medium, and high ranges of TOC, respectively. The values for all group comparisons in Table 2 are significantly different from a probability of 0.5 (all p < 0.0001). These are the Type I error probabilities associated with rejecting the null hypothesis that when comparing samples taken from 2 groups, the probability of observing reduced species richness in the higher TOC range is equal to 0.5 based on 1 -sided $t$-tests. Based on these results, it appears that there is high predictive ability across the TOC ranges defined by these critical points.

A further demonstration of the predictive ability of these TOC critical points as an indicator of benthic stress is given in Table 3, which provides a comparison of species richness and various measures of the prevalence of degraded environmental condition across the 3 TOC ranges. The comparison focuses on data from estuaries of the southeastern USA, where a benthic condition index and related sediment-quality targets have been developed for assessing prevalence of degraded benthic condition and other adverse sediment conditions (e.g. high concentrations of chemical contamination at levels likely of causing adverse effects on benthic fauna). Methods were not available to make such comparisons with the other data sets. The degraded benthic condition was evaluated using a multi-metric, benthic index of biotic integrity (B-IBI) based on the methods of Van Dolah et al. (1999). High sediment contamination was defined using guidelines presented in Hyland et al. (1999). Also, dissolved oxygen (DO) $<2 \mathrm{mg} \mathrm{l}^{-1}$ was used as a criterion for evaluating low DO potentially harmful to bottomdwelling fauna (see review by Diaz \& Rosenberg 1995). As expected, there are very low percentages of samples with degraded benthic condition and high sediment contamination (7.6 and $3.5 \%$, respectively) within the low TOC range $\left(\leq 10 \mathrm{mg} \mathrm{g}^{-1}\right)$ and a much higher percentage $(78$ and $90 \%$, respectively) within the high TOC range
Table 2. Results of re-sampling simulation to evaluate the probability of observing high, medium, and low species richness within low, moderate, and high TOC ranges, defined by critical points at 10 and $35 \mathrm{mg} \mathrm{g}^{-1}$. Simulations consist of 10 iterations of 250 pairwise comparisons. p-values are the Type I error probabilities associated with rejecting the null hypothesis that when comparing samples taken from 2 groups, the probability of observing reduced species richness in the higher TOC range is equal to 0.5 based on 1-sided $t$-tests. Subscripts 1, 2, and 3 in the group comparison column refer to low, moderate, and high ranges of TOC, respectively

\begin{tabular}{|ccc|}
\hline Group comparison & Probability of occurrence & p-value \\
\hline$E\left(S_{10}\right)_{1}>E\left(S_{10}\right)_{2}$ & $0.70 \pm 0.02$ & $<0.0001$ \\
$E\left(S_{10}\right)_{1}>E\left(S_{10}\right)_{3}$ & $0.91 \pm 0.01$ & $<0.0001$ \\
$E\left(S_{10}\right)_{2}>E\left(S_{10}\right)_{3}$ & $0.81 \pm 0.01$ & $<0.0001$ \\
\hline
\end{tabular}

(>35 $\mathrm{mg} \mathrm{g} \mathrm{g}^{-1}$ ). An intermediate percentage of degraded condition, based on these measures, occurs within the middle TOC range. Note that the percentage of samples with low DO $\left(<2 \mathrm{mg} \mathrm{l}^{-1}\right)$ in near-bottom water also increases with increasing TOC concentration, although the prevalence of this effect does not reach a very high percentage even within the highest TOC range (only $24 \%$ ). Mean values of $E\left(S_{10}\right)$ also show a continuous decline across the 3 TOC ranges. These results are consistent with the above conceptual model predictions, and further illustrate that the TOC critical points, while not a measure of causality themselves, may serve as a surrogate indicator of stress induced by other co-varying factors. Based on this example, the cutoff points appear to be realistic and predictive of a disturbed condition when other evidence of disturbance exists.

Table 3. Comparison of mean values of benthic species richness $\left(E\left(S_{10}\right)\right)$ and prevalence of degraded environmental condition (based on 3 different biological, chemical, and physical indicators) within 3 ranges of total organic carbon (TOC) in estuaries of the southeastern USA. TOC ranges are based on critical points at 10 and $35 \mathrm{mg} \mathrm{g}^{-1}$. Values in parentheses are number of samples. B-IBI: benthic index of biotic integrity; ERM: 'effect range median' sediment quality guidelines (Long et al. 1995); DO: dissolved oxygen

\begin{tabular}{|lccc|}
\hline & \multicolumn{3}{c|}{ TOC $\left(\mathrm{mg} \mathrm{g}^{-1}\right)$} \\
& $\leq 10$ & $10-35$ & $>35$ \\
\hline Mean $E\left(S_{10}\right)$ & 5.3 & 4.2 & 2.4 \\
& $(171)$ & $(68)$ & $(50)$ \\
Percent samples with degraded benthos & $7.6 \%$ & $54 \%$ & $78 \%$ \\
(B-IBI score 3; sensu Van Dolah et al. 1999) & $(170)$ & $(67)$ & $(50)$ \\
Percent samples with high chemical & $3.5 \%$ & $31 \%$ & $90 \%$ \\
contamination of sediments (mean ERM & $(171)$ & $(68)$ & $(50)$ \\
quotient > 0.058, sensu Hyland et al. 1999) & & & \\
Percent samples with low DO in near- & $0.6 \%$ & $4.5 \%$ & $24 \%$ \\
bottom water (DO < 2 mg l-1, sensu & $(170)$ & $(67)$ & $(50)$ \\
Diaz \& Rosenberg 1995) & & & \\
\hline
\end{tabular}




\section{DISCUSSION}

\section{Regional comparisons}

There was a general pattern of decreasing species richness from low to high TOC ranges (Table 4$). E\left(S_{10}\right)$ for all regions combined averaged 6.3 in the low TOC range, 5.0 in the intermediate range, and 2.9 in the high range. This general pattern was consistent across most individual data sets, though as noted earlier there were some regional differences (e.g. see Fig. 3B). The main exception was the Seto Inland Sea study, which was represented entirely by stations with TOC in the intermediate range (Table 4). The narrow range in TOC concentrations for this region (12 to $29 \mathrm{mg} \mathrm{g}^{-1}$, Fig. 5) reflects the limited number and localized nature of sampling points (i.e. total of only 18 sampling points from 3 subtidal locations in a tidal estuary). The mean value of $E\left(S_{10}\right)$ for Seto Inland Sea samples, however, was similar to those calculated from samples within this same TOC range for other regions (Table 4). Another exception was the northern Black Sea, where mean $E\left(S_{10}\right)$ was slightly higher within the middle than lower TOC range, though the pattern of lowest values within the uppermost TOC range was still observed.

The strongest pattern in species richness was represented by samples from the eastern Mediterranean Sea (Table 4$)$. Mean $E\left(S_{10}\right)$ for these samples was 3.5 times higher in the low TOC range than in the high TOC range. The magnitude of this change is due at least in part to the initially high level of species richness observed within the low TOC range, i.e. mean $E\left(S_{10}\right)$ of 8.0, which was much larger than corresponding values for all other regions (Table 4). The fauna and flora of the eastern Mediterranean Sea are known as being highly diverse, with a large proportion of endemic species due to the region's dynamic geological past (Tortonese 1985, Fredj et al. 1992). Additionally, in this generally oligotrophic region (see discussion below) it may be that benthic species richness is more sensitive to organic over-enrichment than in other systems. Conversely, increased organic loading in a naturally eutrophic system might be less likely to cause a problem than in an oligotrophic system.
Table 4. Comparison of mean values of benthic species richness $\left(E\left(S_{10}\right)\right)$ within different ranges of total organic carbon (TOC, $\mathrm{mg} \mathrm{g}^{-1}$ ) by study region

\begin{tabular}{|lccc|}
\hline Study region & \multicolumn{3}{c|}{ TOC ranges $\left(\mathrm{mg} \mathrm{g}^{-1}\right)$} \\
& $\leq 10$ & $>10-35$ & $>35$ \\
\hline Eastern Mediterranean Sea & 8.0 & 5.5 & 2.3 \\
North Sea \& coastal UK & 7.8 & 6.4 & 4.6 \\
Boston Harbor \& Massachusetts Bay, USA & 5.9 & 5.4 & 2.9 \\
Estuaries of SE USA & 5.3 & 4.2 & 2.4 \\
Northern Black Sea & 4.0 & 4.2 & 3.5 \\
Estuary of Seto Inland Sea, Japan & - & 4.3 & - \\
All regions (pooled) & 6.3 & 5.0 & 2.9 \\
\hline
\end{tabular}

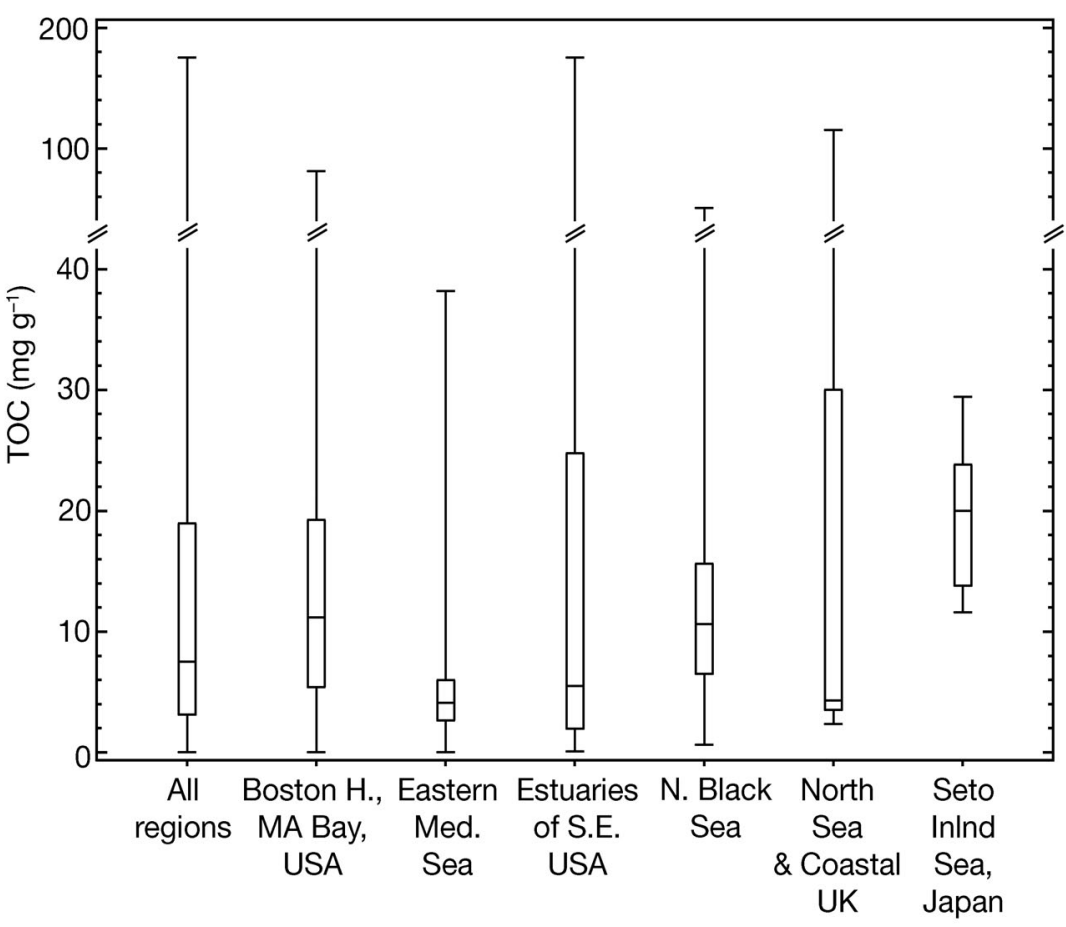

Fig. 5. Box-and-whisker plots of total organic carbon (TOC, $\mathrm{mg} \mathrm{g}^{-1}$ ) by study region. Boxes are inter-quartile ranges; horizontal lines within boxes are medians; whisker endpoints are high/low extremes

A comparison of TOC concentrations among regions is presented in Fig. 5. Eastern Mediterranean waters are characteristically oligotrophic (Bethoux 1981, Azov 1986). Present samples from the Cretan shelf had TOC concentrations that were consistent with this view. The inter-quartile range of TOC values among these samples was much lower in comparison to the other regions and revealed that most samples $(75 \%)$ were in the low range $<6 \mathrm{mg} \mathrm{g}^{-1}$. Higher TOC levels for these waters were mostly in areas close to point-source discharges of organic wastes, e.g. beneath fish aquaculture cages (Karakassis et al. 1998). Most stations from the other regions had low to intermediate TOC levels, resulting in inter-quartile ranges between about 3 and $30 \mathrm{mg} \mathrm{g}^{-1}$. Estuaries of the southeastern USA exhibited 
the widest range in TOC concentrations, with values up to $175 \mathrm{mg} \mathrm{g}^{-1}$.

\section{Implications for global monitoring and data uncertainty}

We have attempted here to provide a general framework for evaluating risks of reduced benthic species richness from organic loading and associated stressors in sediments within different ranges of TOC. Results suggest that the likelihood of such impairments should be relatively low at TOC concentrations less than about $10 \mathrm{mg} \mathrm{g}^{-1}$, high at concentrations greater than about $35 \mathrm{mg} \mathrm{g}^{-1}$, and intermediate at concentrations in between. Hopefully this framework will prove useful in sediment risk assessments over broad coastal areas that are receiving organic wastes and other co-varying pollutants associated with human activities. However, it must be understood that the TOC critical points supporting this framework are intended to be used only as a general screening-level indicator for evaluating the likelihood of reduced sediment quality and associated bioeffects, and should not be regarded as absolute criteria or measures of causality. No attempt has been made to distinguish between causes of effects directly related to TOC versus other potential co-occurring stressors within these ranges.

Predictive ability across these ranges, though reasonable based on results of re-sampling simulation (Table 2), is not free of uncertainty. This point is illustrated in Fig. 4 by the wide range in species richness values that can be observed at discrete levels of TOC. There is much scatter in the raw data. Methodological differences among the various regional data sets could be a possible source. While steps have been taken to help compensate for such differences (see 'Materials and methods'), related problems still may exist. For example, $E\left(S_{n}\right)$ was selected as a biological response variable to help account for sample-size differences due to different gear types (grab and sieve sizes). Yet finer sieves have been shown to retain greater numbers of small species and of juveniles of larger species retained as adults on coarser sieves (e.g. Bachelet 1990, Schlacher \& Wooldridge 1996, Thompson et al. 2003). The increases could affect both the richness and evenness components of diversity and, thus, the $E\left(S_{n}\right)$ measure. Such potential effects are acknowledged here. However, while mesh-size variations have been shown to have strong influences on estimates of density and biomass, reports of similar effects on measures of species diversity, especially from mesh variations within the 1.0 to $0.3 \mathrm{~mm}$ range used in this study, are less consistent. Bishop \& Hartley (1986) and Thompson et al. (2003), for example, found that few additional species were retained with $0.5 \mathrm{~mm}$ sieves compared to $1.0 \mathrm{~mm}$ sieves. Bachelet (1970), while expounding on the significant loss of individuals with coarser sieves, also found no significant differences in number of taxa among mesh sizes from 0.5 to $0.063 \mathrm{~mm}$ consistently on 4 seasonal sampling occasions, nor in $H^{\prime}$ (Shannon diversity) or $J$ (evenness) among mesh sizes from 1.0 to $0.063 \mathrm{~mm}$ for most sampling occasions. Similarly, with respect to $E\left(S_{10}\right)$, one of the present co-authors (I. Karakassis pers. obs.) compared values of this measure for 87 samples from the eastern Mediterranean Sea that had been sequentially sieved on $1.0 \mathrm{~mm}$ and $0.5 \mathrm{~mm}$ sieves and found no significant differences between mesh sizes. Values calculated from both fractions combined averaged $98 \%( \pm 11 \%)$ of the $1.0 \mathrm{~mm}$ fraction alone. Moreover, while we cannot rule out the possibility of mesh-size effects, it is important to recognize the basic similarity in benthic-TOC patterns observed among the individual regional data sets in the present study (Fig. 3B). Although individual curve elevations varied, the overall pattern of decreasing species richness with increasing TOC was generally consistent among individual data sets including representatives of the various sieve sizes (e.g. $0.3 \mathrm{~mm}$ for Boston Harbor/Massachusetts Bay, $0.5 \mathrm{~mm}$ for eastern Mediterranean Sea and southeastern US estuaries, and $1.0 \mathrm{~mm}$ for North Sea/coastal UK).

In addition to regional differences, the variability in the data could be due to a complexity of other interacting environmental factors, including season, depth, salinity, grain size, sediment hydrodynamics, particle flux, larval supply, food value of organic matter, biological interactions, or presence of other co-varying stressors (see reviews such as Gray 1974, 1981, papers in Coull 1977, Anderson et al. 1987, Lamberson et al. 1992, Snelgrove \& Butman 1994). A particularly good example of this complexity is the growing realization that, in addition to the quantity of organic matter present in sediments, differences in its quality, bioavailability, fluxes, and utilization as a food source can have strong effects on patterns of distribution as well (Gray 1974, Tenore et al. 1982, Lopez \& Levinton 1987 , papers in Lopez et al. 1989, Snelgrove \& Butman 1994).

We also mentioned earlier the importance of grain size as a correlate of TOC and other potential covarying stressors that may be affecting the benthos. Note the direct relationship between the percent fine grains ( $<62 \mu \mathrm{m}$ fraction) and increasing TOC in the present data set and the inverse pattern relative to $E\left(S_{10}\right)$ (Fig. 6). Increasing proportions of finer-grained sediment particles would provide greater surface area (due to a greater surface/volume ratio) for sorption of both organic matter and chemical contaminants (Landrum \& Robbins 1990, Lamberson et al. 1992). Thompson \& Lowe (2004) similarly showed how changes in 
benthic species composition and abundances are often linked to the interaction of fine sediments, organic material, and chemical contaminants. On a related note, a common view explaining higher abundances of deposit-feeding infauna in muddy versus sandy sediments is that there is more food associated with finer particles, due to the greater surface area for microbial growth and adsorption of organic films (Lopez \& Levinton 1987). Snelgrove \& Butman (1994) discuss a number of additional ways in which benthic species may vary in relation to grain size, including preferential selection of settling larvae for a particular size class, preferences for a particular grain size in feeding, exclusion of filter feeders in muddy sediments due to increased resuspension from sediment reworking by deposit feeders (i.e. trophic-group amensalism, as originally introduced by Rhoads \& Young 1970), sediment stability, and the possibility that passively settling benthic larvae and sediments of similar characteristics (e.g. size, specific gravity, and gravitational fall velocity) may be hydrodynamically sorted in a similar manner within the bottom boundary-layer flow.

Thus, such inherent variability and resulting data uncertainty must be considered in future applications of the TOC critical points presented here. Low species richness does not necessarily imply that the system is under stress, or that the cause of stress, if it exists, is due to TOC per se. Low species richness might occur in sediments with low to moderate TOC for such reasons as (1) insufficient amounts of organic matter with nutritionally rich components that can be utilized as food; (2) natural influence of salinity or grain size; (3) geochemical, physical, and hydrodynamic factors restrict-

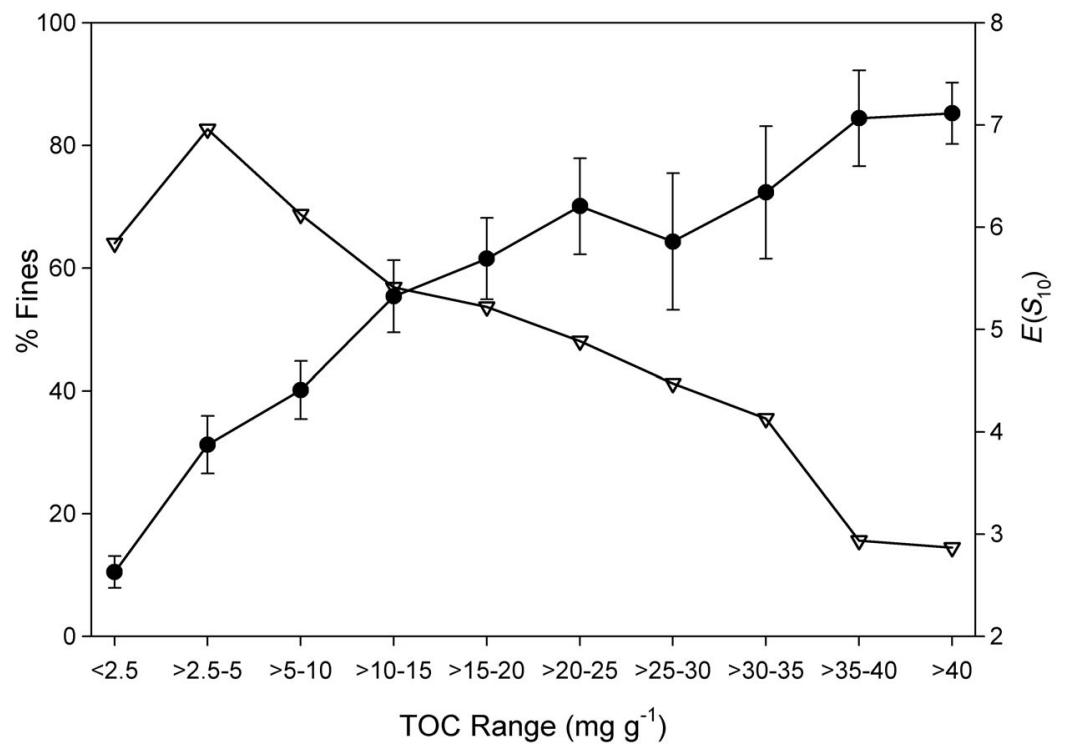

Fig. 6. Plot of the percent fine-grained sediment (<62 mm fraction) and $E\left(S_{10}\right)$ versus TOC $\left(\mathrm{mg} \mathrm{g}^{-1}\right)$. ๑: percent fine-grained sediment; $\nabla: E\left(S_{10}\right)$ ing recruitment of larvae; (4) natural physical disturbances (e.g. sediment erosion due to bottom currents and storm events); or (5) biological interactions (e.g. competition, predation, trophic-group amensalism) (Gray 1974, 1981, papers in Coull 1977, Lopez \& Levinton 1987, papers in Lopez et al. 1989, Snelgrove \& Butman 1994). A variety of anthropogenic factors could contribute to such variability and potential misclassifications as well. For example, chemical contaminants could be present in toxic amounts at a particular site that was not organically enriched, even though such stressors are generally positively correlated with TOC (Landrum \& Robbins 1990, Lamberson et al. 1992, Thompson \& Lowe 2004). Physical disturbances of sediment caused by human activities (e.g. dredging and disposal operations, ground-fishing) also could reduce species richness independent of TOC.

Similarly, it is possible for species-rich benthic assemblages to occur in sediments with high TOC. Possible explanations for such cases include (1) the fauna were not exposed to harmful levels of stressors due to small-scale spatial variations or pollution-tolerance adaptations (Gray 1974, 1981, Pearson \& Rosenberg 1978, Landrum \& Robbins 1990); (2) stressors were present at high concentrations, but not in bioavailable forms (Neff 1984, Adams 1987, Reynoldson 1987, Rodgers et al. 1987, Knezovich et al. 1987, Landrum \& Robbins 1990); or (3) a significant portion of the measured TOC was in a refractory form (e.g. black carbon) and not reflective of related conditions, such as hypoxia or high ammonia and sulphides, that would pose biological risks. Regarding the latter point, it has been shown that black carbon may contribute considerably to the organic matter buried in marine sediments (Middelburg et al. 1999). In the present study, which relied on the use of historical data, there was no way available to go back and identify the quality of carbon present across the various samples and thus to account for such variability uniformly across all samples.

Future research should focus on reducing such uncertainties. Of particular importance for coastal management applications is the need to differentiate between the relative contributions of multiple stressors (e.g. those related to chemical versus organic loading) that may be co-varying in relation to common environmental factors (such as the percent of fine-grained sediment). Condition of the ambient benthic community can be a sensitive indicator of anthropogenic disturbances. However, 
the incidence of a degraded benthic community in organically enriched sediments does not preclude the possibility that the observed bioeffects were due to other co-varying stressors (e.g. chemical contaminants). Where co-occurrences of high TOC levels and benthic effects are observed, detailed follow-up studies are recommended to determine exact causes and stressor sources.

Acknowledgements. This study was conducted by members of the IOC Study Group on Benthic Indicators, an international group of scientists formed under the auspices of the Intergovernmental Oceanographic Commission (IOC) of the United Nations Educational Scientific and Cultural Organization (UNESCO). The work of the group was initiated by the Science on Ocean Ecosystems and Marine Environmental Protection (SOEMEP) Programme. Special appreciation is extended to Dr. U. Unluata, Head of the Ocean Sciences Section of IOC, who got the committee off the ground and thus made this work possible. In addition, we thank B. Coull from the Biostatistics Department at the Harvard School of Public Health for his valuable input on statistical analyses. We wish to acknowledge our respective institutions (see affiliations at beginning of paper) for allowing us to spend time on this important initiative and other pertinent support. Lastly, we thank the 4 anonymous MEPS reviewers who provided very helpful comments on the draft manuscript.

\section{LITERATURE CITED}

Adams WJ (1987) Bioavailability of neutral lipophilic organic chemicals contained in sediments: a review. In: Dickson A, Maki W, Brungs WA (eds) Fate and effects of sediment-bound chemicals in aquatic systems. SETAC Special Publication Series. Pergamon Press, New York, p 219-244

Anderson J, Birge W, Gentile J, Lake J, Rogers J Jr, Swartz R (1987) Biological effects, bioaccumulation, and ecotoxicology of sediment-associated chemicals. In: Dickson A, Maki W, Brungs WA (eds) Fate and effects of sedimentbound chemicals in aquatic systems. SETAC Special Publication Series. Pergamon Press, New York, p 267-295

Azov YJ (1986) Seasonal patterns of phytoplankton productivity and abundance in near-shore oligotrophic waters of the Levant Basin (Mediterranean). J Plankton Res 8:41-53

Bachelet G (1990) The choice of a sieving mesh size in the quantitative assessment of marine macrobenthos: a necessary compromise between aims and constraints. Mar Environ Res 30:21-35

Bates DM, Watts DG (1988) Nonlinear regression analysis and its applications. John Wiley \& Sons, New York

Bethoux JP (1981) Le phosphore et l'azote en Mediterranée, bilans et fertilité potentielle. Mar Chem 10:141-158

Bishop JDD, Hartley JP (1986) A comparison of the fauna retained on 0.5 and $1.0 \mathrm{~mm}$ meshes from benthic samples taken in the Beatrice Oilfield, Moray Firth, Scotland. Proc R Soc Edinb 91B:247-262

Blake JA, Williams IP, Gallagher ED, Hecker B, Rhoads DC, Arnofsy PL (1998) Massachusetts Bay outfall monitoring program: benthic biology and sedimentology baseline monitoring for 1997 and retrospective analysis of the 1992-1997 database. Technical Report ENQUAD 98-16. Massachusetts Water Resources Authority, Boston, MA
Cairns J Jr, McCormick PV, Niederlehner BR (1993) A proposed framework for developing indicators of ecosystem health. Hydrobiologia 263:1-44

Connell JH (1978) Diversity in tropical rain forests and coral reefs. Science 199:1302-1310

Coull BC (ed) (1977) Ecology of marine benthos. University of South Carolina Press, Columbia, SC

Diaz RJ, Rosenberg R (1995) Marine benthic hypoxia: a review of its ecological effects and the behavioural responses of benthic macrofauna. Oceanogr Mar Biol Annu Rev 33:245-303

Fisher WS, Jackson LE, Suter GW II, Bertram P (2001) Indicators for human and ecological risk assessment: a U.S. Environmental Protection Agency perspective. Hum Ecol Risk Assess 7:961-970

Fredj G, Bellan-Santini D, Menardi M (1992) Etat des connaissances sur la faune marine Mediterraneenne. Bull Inst Oceanogr Monaco 9:133-145

Gray JS (1974) Animal-sediment relationships. Oceanogr Mar Biol Annu Rev 12:223-261

Gray JS (1981) The ecology of marine sediments: an introduction to the structure and function of benthic communities. Cambridge University Press, Cambridge

Gray JS, Clarke KR, Warwick RM, Hobbs G (1990) Detection of initial effects of pollution on marine benthos: an example from the Ekofisk and Eldfisk oilfields, North Sea. Mar Ecol Prog Ser 66:285-299

Gray JS, Wu RS, Or YY (2002) Effects of hypoxia and organic enrichment on the coastal marine environment. Mar Ecol Prog Ser 238:249-279

Grime JP (1973) Competitive exclusion in herbaceous vegetation. Nature 242:344-347

Horn HS (1975) Marcovian properties of forest succession. In: Cody ML, Diamond JM (eds) Ecology and evolution of communities. Belknap Press, Cambridge, MA, p 196-211

Hurlbert SH (1971) The nonconcept of species diversity: a critique and alternative parameters. Ecology 52:577-586

Hyland JL, Snoots TR, Balthis WL (1998) Sediment quality of estuaries in the southeastern US. Environ Monit Assess 51: 331-343

Hyland JL, Van Dolah RF, Snoots TR (1999) Predicting stress in benthic communities of southeastern U.S. estuaries in relation to chemical contamination of sediments. Environ Toxicol Chem 18:2557-2564

Karakassis I, Eleftheriou A (1997) The continental shelf of Crete: structure of macrobenthic communities. Mar Ecol Prog Ser 160:185-196

Karakassis I, Tsapakis M, Hatziyanni E (1998) Seasonal variability in sediment profiles beneath fish farm cages in the Mediterranean. Mar Ecol Prog Ser 162:243-252

Karakassis I, Hatziyanni E, Tsapakis M, Plaiti W (1999) Benthic recovery following cessation of fish farming: a series of successes and catastrophes. Mar Ecol Prog Ser 184: 205-218

Karakassis I, Tsapakis M, Hatziyanni E, Papadopoulou KN, Plaiti W (2000) Impact of bass and bream farming in cages on the seabed in three Mediterranean coastal areas. ICES J Mar Sci 57:1462-1471

Knezovitch JP, Harrison FL, Wilhelm RG (1987) The bioavailability of sediment-sorbed organic chemicals: a review. Water Air Soil Pollut 32:233-245

Lamberson JO, DeWitt TH, Swartz RC (1992) Assessment of sediment toxicity to marine benthos. In: Burton GA Jr (ed) Sediment toxicity assessment. Lewis Publishers, Boca Raton, FL, p 183-211

Lampadariou N, Karakassis I, Chapdelaine L, Wilkinson MF, Dafnomili E (2000) Spatial variability in water column and 
sediment chemistry in Heraklion harbour (Crete, E. Mediterranean). Fresenius Environ Bull 9:164-171

Landrum PF, Robbins JA (1990) Bioavailability of sedimentassociated contaminants to benthic invertebrates. In: Baudo R, Giesy JP, Muntau H (eds) Sediments: chemistry and toxicity of in-place pollutants. Lewis Publishers, Ann Arbor, MI, p 237-263

Leong LS, Tanner PN (1999) Comparison of methods for determination of organic carbon in marine sediment. Mar Pollut Bull 38:875-879

Long ER, MacDonald DD, Smith SL, Calder FD (1995) Incidence of adverse biological effects within ranges of chemical concentrations in marine and estuarine sediments. Environ Manage 19:81-97

Lopez GR, Levinton JS (1987) Ecology of deposit-feeding animals in marine sediments. Q Rev Biol 62:235-260

Lopez G, Taghon G, Levinton J (eds) (1989) Ecology of marine deposit feeders. Lecture Notes on Coastal and Estuarine Studies 31. Springer, New York

Lunneborg CE (1999) Data analysis by resampling: concepts and applications. Brooks/Cole Publishing, Pacific Grove, CA

Magni P (1998) A multidisciplinary study on the dynamics of biophilic elements $(\mathrm{C}, \mathrm{N}, \mathrm{P}, \mathrm{Si})$ in a tidal estuary of the Seto Inland Sea, Japan: physico-chemical variability and macrozoobenthic communities. PhD thesis, The United Graduate School of Ehime University, Ehime

Middelburg JJ, Nieuwenhuize J, van Breugel P (1999) Black carbon in marine sediments. Mar Chem 65:245-252

Mironov OG, Kiryukhina L, Divavin I (1992) Sanitary and biological studies in the Black Sea. Hydrometeoizdat Publishers, St. Petersburg (in Russian)

Neff J (1984) Bioaccumulation of organic micropollutants from sediments and suspended particulates by aquatic animals. Fresenius Z Anal Chem 319:132-136

Pearson TH, Blackstock J (1984) Garroch Head sludge dumping ground survey, final report. Dunstaffnage Marine Research Laboratory, Oban, Argyll

Pearson TH, Rosenberg R (1978) Macrobenthic succession in relation to organic enrichment and pollution of the marine environment. Oceanogr Mar Biol Annu Rev 16:229-311

Petrov AN (2000a) Responses of the Black Sea macrobenthic communities upon organic enrichment impact of bottom sediments. Ehkol Morya 51:56-60 (in Russian, abstract in English)

Petrov AN (2000b) Benthic monitoring in the northern Black Sea. In: Hyland JL, Karakassis I, Magni P, Petrov AN, Shine JP (eds) Ad hoc benthic indicator group - results of initial planning meeting, 6-9 Dec 1999. IOC Technical Series No. 57. UNESCO Intergovernmental Oceanographic Commission (IOC), Paris

Reynoldson TB (1987) Interactions between sediment

Editorial responsibility: Otto Kinne (Editor-in-Chief),

Oldendorf/Luhe, Germany contaminants and benthic organisms. Hydrobiologia 149: $53-66$

Rhoads DC, Young DK (1970) The influence of depositfeeding organisms on sediment stability and community trophic structure. J Mar Res 28:150-178

Rodgers JH, Dickson KL, Saleh FY, Staples CA (1987) Bioavailability of sediment-bound chemicals to aquatic organisms - some theory, evidence and research needs. In: Dickson A, Maki W, Brungs WA (eds) Fate and effects of sediment-bound chemicals in aquatic systems. SETAC Special Publication Series. Pergamon Press, New York, p 245-266

Sanders HL (1958) Benthic studies in Buzzards Bay. I. Animalsediment relationships. Limnol Oceanogr 3:245-258

Schlacher TA, Wooldridge TH (1996) How sieve mesh size affects sample estimates of estuarine benthic macrofauna. J Exp Mar Biol Ecol 201:159-171

Shannon CE, Weaver W (1949) The mathematical theory of communication. University of Illinois Press, Urbana, IL

Snelgrove PVR, Butman CA (1994) Animal-sediment relationships revisited: cause versus effect. Oceanogr Mar Biol Annu Rev 32:111-177

Sokal RR, Rohlf FJ (1981) Biometry, 2nd edn. WH Freeman, New York

Somerfield PJ, Rees HL, Warwick RM (1995) Interrelations in community structure between shallow-water marine meiofauna and macrofauna in relation to dredgings disposal. Mar Ecol Prog Ser 127:103-112

Tenore KR, Cammen L, Findlay SEG, Phillips N (1982) Perspectives of research on detritus: do factors controlling the availability of detritus to macroconsumers depend on its source? J Mar Res 40:473-490

Thompson B, Lowe S (2004) Assessment of macrobenthos response to sediment contamination in the San Francisco estuary, California, USA. Environ Toxicol Chem 23: $2178-2187$

Thompson BW, Riddle MJ, Stark JS (2003) Cost-efficient methods for marine pollution monitoring at Casey Station, East Antarctica: the choice of sieve mesh-size and taxonomic resolution. Mar Pollut Bull 46:232-243

Tortonese E (1985) Distribution and ecology of endemic elements in the Mediterranean fauna (fishes and echinoderms). In: Moraitou-Apostolopoulou M, Kiortsis V (eds) Mediterranean marine ecosystems. Plenum Press, New York, p 57-83

Van Dolah RF, Hyland JL, Holland AF, Rosen JS, Snoots TR (1999) A benthic index of biological integrity for assessing habitat quality in estuaries of the southeastern USA. Mar Environ Res 48:269-283

Wilkinson DM (1999) The disturbing history of intermediate disturbance. Oikos 84:145-147

Submitted: April 23, 2003; Accepted: February 23, 2005

Proofs received from author(s): June 6, 2005 